\title{
REAL-TIME MONITORING DEFORMATION OF BUILDING USING PHOTOGRAPHY DYNAMIC MONITORING SYSTEM
}

\author{
Yongquan $\mathrm{Ge}^{1}$, Chengxin $\mathrm{Yu}^{2}$, Tonglong Zhao ${ }^{1}$ and Xiaodong Liu ${ }^{3}$
}

1. Shandong Jianzhu University, College of Surveying and Geo-Informatic, Fengming Road 1000, 250101 Jinan, Shandong, China; ge39953@163.com, zhaotongl@sdjzu.edu.cn

2. Shandong Jianzhu University, Business School, Fengming Road 1000, 250101 Jinan, Shandong, China; ycx1108@126.com (Corresponding author)

3. Shandong Jianzhu University, College of Continuing Education, Shandong Jianzhu University, Fengming Road 1000, 250101 Jinan, Shandong, China

\begin{abstract}
The spatial structure building is a type of building system; it is necessary to monitor deformation to determine its stability and robustness. Under the dynamic deformation of structures, it is challenging to determine appropriate zero image (the reference image) if we use the PST-IMMP (photograph scale transformation-image matching-motion parallax) method to obtain the deformation of structures. This paper offers the Z-MP (zero-centered motion parallax) method to solve these problems and offers PDMS (Photography Dynamic Monitoring System) based on the digital photography system to monitor the dynamic deformation of the tennis stadium located in Jinan Olympic Sports Center. The results showed that the spatial structures of the tennis stadium were robust, and the deformations were elastic and within the permissible value. Compared with the PST-IM-MP method, the Z-MP method is more suitable for deformation monitoring structures under real-time deformation. This paper indicates PDMS has advantages of the simplicity of operations, automation, and the ability of non-contact dynamic deformation monitoring for multiple points in a short period. In the future, it will have broader application prospects.
\end{abstract}

\section{KEYWORDS}

Close-range photogrammetry, Dynamic deformation, The spatial structure, Z-MP (zerocentered motion parallax) method, PDMS (Photography Dynamic Monitoring System), Tennis stadium

\section{INTRODUCTION}

Over the last decade, space structures have evolved and found their usefulness in the modern world, since they are aesthetically appealing and architecturally flexible. They have lightweight profiles that reduce construction costs, stability, and strength, and cover large areas of uninterrupted spans [1]. The large-span spatial structure has been widely used in various large sports venues, theatres, exhibition centers, airport terminals, and various industrial plants. Such buildings are usually places where people gather, and large-scale activities occur, so the safety of the large-span spatial structures is particularly important.

Large-span spatial structures using a large number of new materials such as steel membranes, high strength steel bundles. However, corrosion of materials, uneven settlement of the aging foundation, and coupling effects of complex load fatigue, which will inevitably lead to damage accumulation and resistance attenuation of the structural system, and in extreme cases lead to catastrophic emergencies [2]. For example, the multifunctional stadium in Kuala Lumpur, 
Malaysia collapsed caused design and construction quality in June 2009 [3]; overloading of the main roof structure caused the roof to collapse during the expansion of De Grolsch Veste FC Twente stadium in the Netherlands In July 2011 [4]; due to the accumulation of rain, the platform of the roof structure is thicker than the original design, and the greening vegetation laid by hall exceeds the load, finally leading to the city university of Hong Kong on the roof of the Chen dahe collapse in May 2016 [5]. The above examples show that although the spatial structure belongs to the statically indeterminate structure, the spatial force is relatively complex. When the damage occurs in the structure's critical parts, the whole structure may be destroyed quickly [6]. According to the collapse accident, the space structure will collapse in a few minutes, even seconds. Therefore, it is important to regularly monitor the deformation of large-span spatial structure and evaluate the structure's status timely.

There are various established methods used in experimental testing to conduct dynamic deformation monitoring. The conventional method used is the attachment of contact sensors such as strain gauges, accelerometers, and Fiber Bragg grating sensors on the structure [7, 8]. Among them, the fiber Bragg grating sensor abandons the traditional measurement method of the electrical signal. It adopts all-optical measurement, which has the advantages of substantial antielectromagnetic interference, good anti-corrosion ability, excellent reliability, and long service life. However, this method can only obtain the 1-D deformation of specific points within a limited measurement range and cannot provide the overall deformation data of the structure [9]. The more sensors are used in theory, and the more accurate the obtained results will be. Therefore, it is necessary to reasonably allocate the number of installed sensors in the actual measurement. How to balance effectiveness and economy is a critical problem to be solved in the arrangement of measuring points of this method [10]. Undoubtedly, the problem increases the sensor layout time, and this method has many limitations of contact measurement. Relevant scholars have conducted extensive research on contactless deformation monitoring technology to solve the above problems and overcome these defects.

The optical technology as a non-contacting measurement technique has gained more attention in the last few decades, mainly because of its non-destructive imaging characteristics with high precision and sensitivity [11-13]. It has seen many advances in recent years that have manifested itself because of the exceptional advances in computer technology and camera sensors. Generally, the optical measurement techniques can be classified into two main categories: (a) approaches that use laser beams and (b) approaches that use white light. Laser surface scanners are based on laser beams, which move across the scanned surface and reflect to a light sensor [14]. The second class works by using white light and is called image-based systems. The photogrammetry technique falls into the second group and leverages rays of light that are reflected from a structure [9].

Some scholars have successfully applied photogrammetry technology to the deformation monitoring of engineering structures such as steel structures [15], bridges structures [16], regulating sluice structures [17], and shuttle steel shelves [18]. The DLT (direct linear transformation) method and the MP (motion parallax) method are two conventional methods used to obtain the deformation of the monitoring points. The DLT method is only suitable for a small range of measurements, and this method has high requirements for control points. The MP method is mainly used for obtaining the 2-D plane deformation and the relative variation of monitoring points. However, internal and external orientation elements are always changing during the measurement process. The IM-MP (image matching-motion parallax) method is used to correct the influence of this phenomenon on the measurement results and to improve the measurement accuracy, the PST-IM-MP (photograph scale transformation-image matching-motion parallax) method to solve the problem of the reference points and the monitoring points are not on the same plane [18]. However, since the algorithm is based on the comparison between the successive image and the zero image to obtain the deformation of monitoring points, the visualization results are not user-friendly. For the buildings that have been in dynamic deformation, we obtain $X-Z$ 
plane deformation by using the $X$ and $Z$ direction deformations is inappropriate. This paper proposed the Z-MP method will solve the above problems and conducted a monitoring dynamic deformation test on the tennis stadium of Jinan Olympic Sports Center in China. In this paper, the test results of the two methods were compared.

\section{PHOTOGRAPHY DYNAMIC MONITORING SYSTEM}

PDMS consists of two parts: information acquisition and information processing. The information acquisition consists of a digital camera, a distance finder and two tripods. The information processing is a computer with the photography dynamic monitoring software installed. The software can process images and output of deformation results. Figure 1 shows the view of PDMS. The view and parameters of the distance finder are shown in Figure 2 and Table 1, respectively.

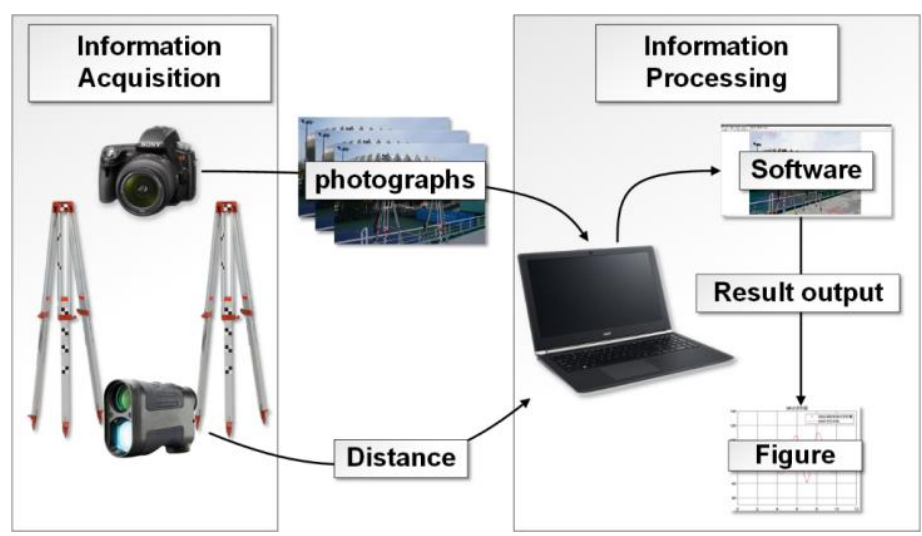

Fig. 1 - Photography dynamic monitoring system

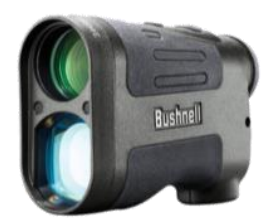

Fig. 2 - Images of the distance finder

Tab. 1 - Parameters of the distance finder

\begin{tabular}{|c|c|}
\hline model & Bushnell PRIME 1200 \\
\hline range & $7-1200 \mathrm{Y}$ \\
\hline accuracy & $\pm 1 Y$ \\
\hline
\end{tabular}

\section{Camera and its distortion}

In this paper, we used a Sony- $\alpha 350$. The view and parameters of the camera are shown in Figure 3 and Table 2, respectively.
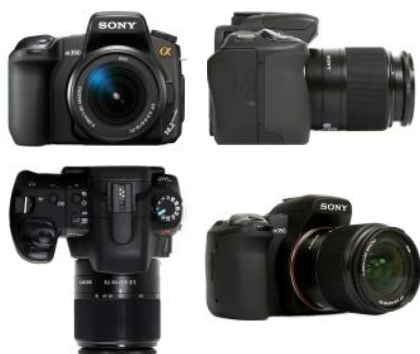

Fig. 3 - Images of the Sony- $\alpha 350$ camera
Tab. 2 - Parameters of the Sony- $\alpha 350$ camera

\begin{tabular}{|l|l|}
\hline Model ID & DSLR-A350 \\
\hline Image Sensor & CCD \\
\hline $\begin{array}{l}\text { Image Sensor } \\
\text { Dimension }\end{array}$ & $23.5 \times 15.7 \mathrm{~mm}$ \\
\hline $\begin{array}{l}\text { Image } \\
\text { Dimension }\end{array}$ & $4592 \times 3056(14.0 \mathrm{MP})$ \\
\hline Lens Type & $\begin{array}{l}\text { Minolta / Sony AF DT 18 - } \\
70 \mathrm{~mm} \text { F3.5 - 5.6 (D) }\end{array}$ \\
\hline
\end{tabular}


Because the sensitive element of the non-metric digital camera used in this paper is CCD, the camera parameters are unknown and unstable, which leads to the instability of the imaging process, so there is a large lens distortion in the digital image. In order to reduce the interference caused by lens distortion, it is necessary to correct the lens distortion. The correction method used in this paper is a grid-based method [19]. Figure 4 (a) is the nine $\times$ nine grid used in this paper, which is printed on ISO-AO matte paper. Figure 4 (b) is the analysis diagram of the distortion difference obtained after the analysis of the distortion difference of the grid. Through the analysis and comparison of several groups of distortion errors, the change rule of distortion difference is explored to correct the image distortion. The specific implementation process is as follows:

Step 1: fix the grid on the vertical plane, adjust the digital camera mode to "manual" to ensure constant exposure in the subsequent shooting process, and set it up at a specific distance $S$ from the grid.

Step 2: control the digital camera to shoot the grid many times and record the distance at the same time;

Step 3: take the image with excellent image and the actual grid for careful comparison, through the observation of image feature points, analysis of the digital camera image distortion law;

Step 4: change the distance $S$ before and after without changing the direction, repeat

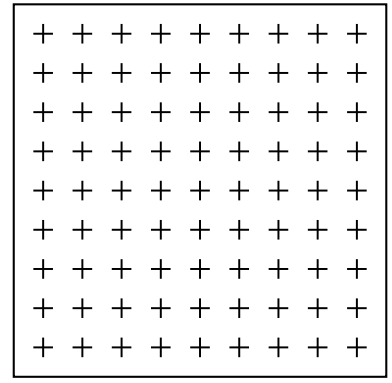

(a) $9 * 9$ grid

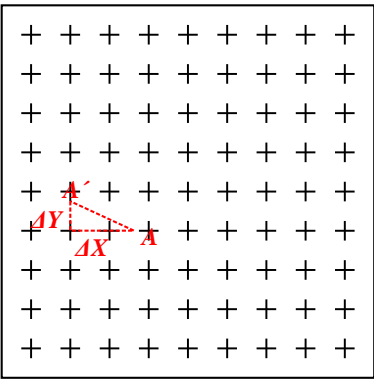

(b) Distortion analysis

Fig. 4 - Camera calibration steps 2 and 3.

Step 5: obtain the mathematical relation of image distortion and complete the distortion correction.

\section{Photography dynamic monitoring software}

Figure 5 shows the software screenshot. The software can obtain the deformation value of multiple monitoring points through the PST-IM-MP method, the Z-MP method, and the MP method. It can also provide sufficient and reliable deformation data, finally forming user-friendly visualization results.

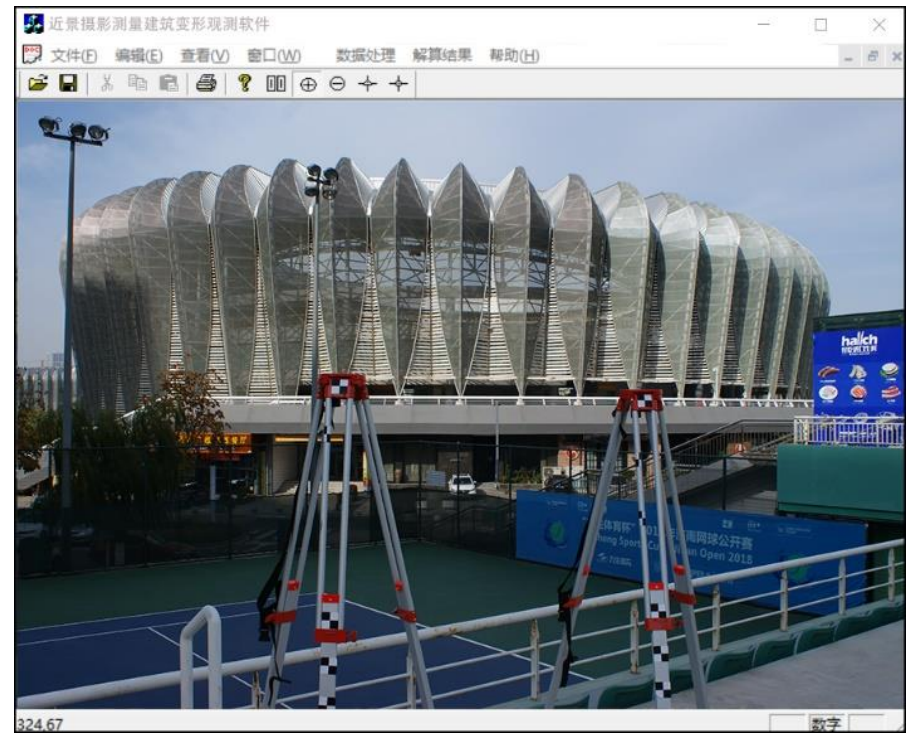

Fig. 5 - Photography dynamic deformation software 
Import the data from the information acquisition part into the computer of the information processing part, and batch process the pictures: Import the images into software and carry out the unified preprocessing of the images as the case may be, such as cutting and drawing. Image processing operations such as binarization, sharpening, and improving contrast or clarity. Input scale deformation values, and then get the pixel position and pixel correction of monitoring points and reference points in the corresponding images, pixel displacement and all other images relative to the reference image the actual displacement of the monitoring point in $\mathrm{mm}$.

\section{The zero-centered motion parallax method}

In Figure 6, suppose there are three planes, image plane, reference plane, and object plane. Image plane is the image of the camera, reference plane is formed by a pair of tripods, object plane is the side of the tennis stadium. And Figure 5 shows the number and distribution of points on a reference plane and a object plane. There are six control points distributed on the reference plane, namely $\mathrm{C} 0-\mathrm{C} 6$, twelve monitoring points on the object plane namely $\mathrm{U} 0-\mathrm{U} 12$. If monitoring point on the object plane is moved from $A$ to $B$, its deformation $\Delta x$ and $\Delta z$ on the reference plane are:

$$
\left.\begin{array}{l}
\Delta x=\frac{y}{f} \Delta P_{x} \\
\Delta z=\frac{y}{f} \Delta P_{z}
\end{array}\right\}
$$

Where $f$ is the principal distance of photo, where $y$ is the distance of the image plane and the reference plane. $\Delta P_{x}$ and $\Delta P_{z}$ are the horizontal and vertical deformations of monitoring point on the image plane. $\Delta x$ and $\Delta z$ are the horizontal and vertical deformations of monitoring point on the reference plane.

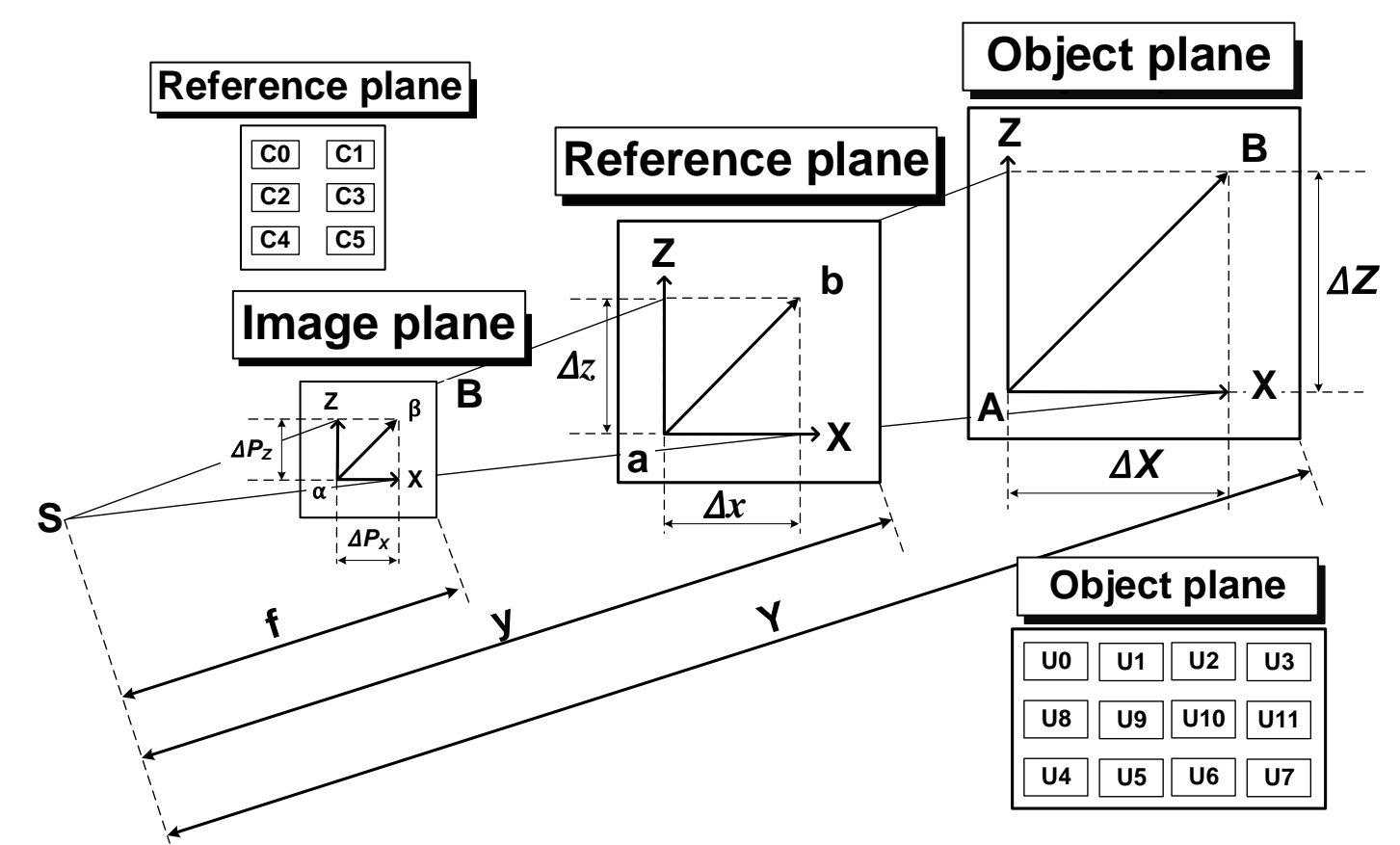

Fig. 6 - Principle of the Z-MP method 


\section{Correction of system errors in the Z-MP method on the reference plane}

Strictly speaking, the photos before and after deformation are always taken under different elements of interior and exterior orientation, the interior orientation elements in a photo are the elements for restoring the shape of the photographic beam, the exterior orientation in a photo are the elements for determining the position and orientation of the photographic beam in the space coordinate system. In the test, we keep the camera as stable as possible and set the digital camera mode to ' manual '. Therefore, the error caused by the inconsistency of elements of interior and exterior orientation will have a slight impact on the monitoring results; we weaken the theoretical error to a certain extent by setting control points. To be exact, we weakened $\Delta x_{p}^{0}$; the specific process is as follows.

On the reference plane, if corresponding monitoring points in the zero image and successive image are $\left(x_{1}, z_{1}\right)$ and $\left(x_{2}, z_{2}\right)$, compared with the ideal image which without errors of camera external and internal parameters, systematic errors of corresponding monitoring point are $\left(\mathrm{d} x_{1}, \mathrm{~d} z_{1}\right)$ and $\left(\mathrm{d} x_{2}, \mathrm{~d} z_{2}\right)$, respectively. The equations can be expressed as Equation (2):

$$
\left.\begin{array}{l}
\left(x_{2}-x_{1}\right)-\left(d x_{2}-d x_{1}\right)-\Delta x=0 \\
\left(z_{2}-z_{1}\right)-\left(d z_{2}-d z_{1}\right)-\Delta z=0
\end{array}\right\}
$$

If there are errors of camera external and internal parameters between the zero image and successive images, the control points located on the reference plane will generate parallax $\Delta x_{p}$ and $\Delta z_{p}$ as Equation (3):

$$
\left.\begin{array}{rl}
\Delta x_{p} & =\left(x_{2}-x_{1}\right)=\left(d x_{2}-d x_{1}\right) \\
\Delta z_{p} & =\left(z_{2}-z_{1}\right)=\left(d z_{2}-d z_{1}\right)
\end{array}\right\}
$$

The parallax $\Delta x_{p}$ and $\Delta z_{p}$ of the control point must be caused by the errors of camera external and internal parameters in successive zero images, we take parallax $\Delta x_{p}$ for example, it can be expressed as Equation (4), the detailed derivation process is shown in the reference[21]:

$$
\begin{aligned}
& \Delta x_{p}=\left(x_{2}-x_{1}\right)=\left(d x_{2}-d x_{1}\right) \\
& =-\left[\frac{f}{Y} d X_{s_{2}}+\frac{d Y_{s_{2}}}{Y} x_{2}+\left(f+\frac{x_{2}^{2}}{f}\right) d \varphi_{2}+\frac{x_{2} z_{2}}{f} d \omega_{2}-z_{2} d \kappa_{2}+\frac{x_{2}}{f} d f_{2}+d x_{0_{2}}\right] \\
& +\left[\frac{f}{Y} d X_{s_{1}}+\frac{d Y_{s_{1}}}{Y} x_{1}+\left(f+\frac{x_{1}^{2}}{f}\right) d \varphi_{1}+\frac{x_{1} z_{1}}{f} d \omega_{1}-z_{1} d \kappa_{1}+\frac{x_{1}}{f} d f_{1}+d x_{0_{1}}\right]
\end{aligned}
$$

Where $\left(\mathrm{d} X_{S_{2}}, \mathrm{~d} Y_{S_{2}}, \mathrm{~d} \varphi_{2}, \cdots\right)$ and $\left(\mathrm{d} X_{S_{1}}, \mathrm{~d} Y_{S_{1}}, \mathrm{~d} \varphi_{1}, \cdots\right)$ are errors of zero image and successive images. From Equation (4), we notice $x_{2}=x_{1}+\Delta x_{p}$, assume the difference between the errors of zero image and successive images as Equation (5) shows:

$$
\begin{aligned}
& \Delta X_{S}=d x_{S_{2}}-d x_{s_{1}} \\
& \Delta Y_{S}=d Y_{S_{2}}-d Y_{s_{1}} \\
& \Delta \varphi=d \varphi_{2}-d \varphi_{1} \\
& \Delta \omega=d \omega_{2}-d w_{1} \\
& \Delta k=d k_{2}-d k_{1} \\
& \Delta f=d f_{2}-d f_{1} \\
& \Delta x_{0}=d x_{0_{2}}-d x_{0_{1}}
\end{aligned}
$$

Then, Equation (4) can be expressed as Equation (6):

$$
\begin{gathered}
\Delta x_{s}=-\frac{f}{Y} \Delta X_{S}-\frac{d Y_{s}}{Y} x_{1}-f \Delta \varphi-\frac{x_{1}^{2}}{f} \Delta \varphi-\frac{x_{1} z_{1}}{f} \Delta \omega+z_{1} \Delta \kappa-\frac{\Delta f}{f} x_{1}-\Delta x_{0}-\Delta x_{p} \frac{d Y_{S_{2}}}{Y} \\
-\Delta x_{p} \frac{2 x_{1}}{f} d \varphi_{2}-\frac{\Delta x_{p} z_{1}}{f} d \omega_{2}-\frac{\Delta z_{p} x_{1}}{f} d \omega_{2}+\Delta z_{p} d \kappa_{2}-\Delta x_{p} \frac{d f_{2}}{f}
\end{gathered}
$$

After sorting out Equation (6), it can be expressed as Equation (7): 


$$
\left.\begin{array}{c}
\Delta x_{p}=\Delta x_{p}^{0}+\delta x_{p} \\
\Delta x_{p}^{0}=\left[\left(-\frac{d Y_{s}}{Y}-\frac{\Delta f}{f}\right) x_{1}+z_{1} \Delta \kappa+\left(-\frac{f}{Y} \Delta X_{S}-f \Delta \varphi-\Delta x_{0}\right)\right]-\frac{x_{1}^{2}}{f} \Delta \varphi-\frac{x_{1} z_{1}}{f} \Delta \omega \\
\delta x_{p}=-\left(\frac{\Delta x_{p} d Y_{S_{2}}}{Y}\right)-\frac{2 \Delta x_{p} x_{1}}{f} d \varphi_{2}-\frac{\Delta x_{p} z_{1}}{f} d \omega_{2}-\frac{\Delta z_{p} x_{1}}{f} d \omega_{2}+\Delta z_{p} d \kappa_{2}-\frac{d f_{2}}{f} \Delta x_{p}
\end{array}\right\}
$$

Because motion $\Delta p_{x}^{0}$ is caused by the change of camera external and internal parameters $\left(\Delta X_{s}, \Delta Z_{s}, \Delta \varphi, \Delta \omega, \Delta \kappa, \Delta f, \Delta x_{0}\right)$ in the successive and zero images, we can correct $\Delta p_{x}^{0}$ with a sufficient number of control points. Differently, motion $\delta p_{x}$ is caused by the interaction of $\Delta x_{p}, \Delta z_{p}$, and camera external and internal parameters $\left(\mathrm{d} Z_{s_{2}}, \mathrm{~d} \varphi_{2}, \mathrm{~d} \omega_{2}, \mathrm{~d} \kappa_{2}, \mathrm{~d} f_{2}\right)$ in the successive image. However, $\Delta x_{p}$ and $\Delta z_{p}$ are different at each point, control points cannot be used to correct $\delta x_{p}$, so we only discuss $\Delta x_{p}^{0}$ as follows:

$$
\Delta x_{p}^{0}=\left(-\frac{\Delta Y_{S}}{Y}-\frac{\Delta f}{f}\right) x_{1}+\Delta \kappa z_{1}+\left(-\frac{f}{Y} \Delta X_{S}-f \Delta \varphi-\Delta x_{0}\right)-\frac{x_{1}^{2}}{f} \Delta \varphi-\frac{x_{1} z_{1}}{f} \Delta \omega
$$

We can express Equation (8) as Equation (9):

$$
\Delta x_{p}^{0}=a x+b z+c+d x^{2}+e x z
$$

If there are more than five control points, each unknown coefficient $(a, b, c, d$, e) can be obtained according to their $\Delta x_{p}^{0}$. We assume the correction of $\Delta x$ is $v$, so the error equation is:

$$
v=a x+b z+c+d x^{2}+e x z-\Delta x
$$

For convenience, we selected the linear part of the Equation (10) for processing, as Equation (11) shows:

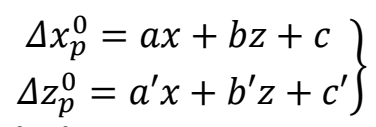

In this case, we only need three or more reference points to obtain $(\boldsymbol{a}, \boldsymbol{b}, \boldsymbol{c})$ and $\left(\boldsymbol{a}^{\prime}, \boldsymbol{b}^{\prime}, \boldsymbol{c}^{\prime}\right)$. Take $\Delta P_{x}^{0}$ as an example, when $\Delta P_{x}^{0}$ contains only occasional errors, Equation (11) can express as Equation (12):

$$
p_{x}^{\prime}+V=a x^{\prime}+b z^{\prime}
$$

Where $p_{x}^{\prime}$ is the differential coefficient of $\Delta P_{x}^{0}$. the error equation is:

The equation of the composition method is:

$$
V=a x^{\prime}+b z^{\prime}-p_{x}^{\prime}
$$

$$
\left.\begin{array}{l}
a \sum x^{\prime 2}+b \sum x^{\prime} z^{\prime}-\sum x^{\prime} p_{x}^{\prime}=0 \\
a \sum x^{\prime} z^{\prime}+b \sum z^{\prime 2}-\sum z^{\prime} p_{x}^{\prime}=0
\end{array}\right\}
$$

Calculate barycentric coordinates by control points on the reference plane.

$$
\left.\begin{array}{l}
x_{s}=x-\frac{\sum x}{n} \\
z_{s}=z-\frac{\sum z}{n}
\end{array}\right\}
$$

Because coordinates of control points are barycentric coordinates, $\sum x_{s} \sum z_{s}=0$ and the parallax coefficient in the $X$ direction as Equation (16) shows:

$$
\left.\begin{array}{l}
a=\frac{\sum z_{s}^{\prime 2} \sum x_{s}^{\prime} p_{x}^{\prime}-\sum x_{s}^{\prime} z_{s}^{\prime} \sum z_{s}^{\prime} p_{x}^{\prime}}{\sum x_{s}^{\prime 2} \sum z_{s}^{\prime 2}-\sum x_{s}^{\prime} z_{s}^{\prime} \sum x_{s}^{\prime} z_{s}^{\prime}} \\
b=\frac{\sum x_{s}^{\prime 2} \sum z_{s}^{\prime} p_{x}^{\prime}-\sum x_{s}^{\prime} z_{s}^{\prime} \sum x_{s}^{\prime} p_{x}^{\prime}}{\sum x_{s}^{\prime 2} \sum z_{s}^{\prime 2}-\sum x_{s}^{\prime} z_{s}^{\prime} \sum x_{s}^{\prime} z_{s}^{\prime}}
\end{array}\right\}
$$


Where $a=\tan \varphi_{x}$ and $b=\tan \omega_{z}$.Similarly, we can obtain the parallax coefficient $a^{\prime}$ and $b^{\prime}$ in the $Z$ direction. Then, we can obtain $\Delta x_{p}^{0}$ and $\Delta z_{p}^{0}$. Finally, we figure out the value of $\Delta x_{p}$ and $\Delta z_{p}$, as Equation (17) shows:

$$
\begin{gathered}
\Delta x_{p} \approx \Delta x_{p}^{0} \approx a x+b z \\
\Delta z_{p} \approx \Delta z_{p}^{0} \approx a^{\prime} x+b^{\prime} z
\end{gathered}
$$

\section{Obtain the deformation of monitoring points on the object plane}

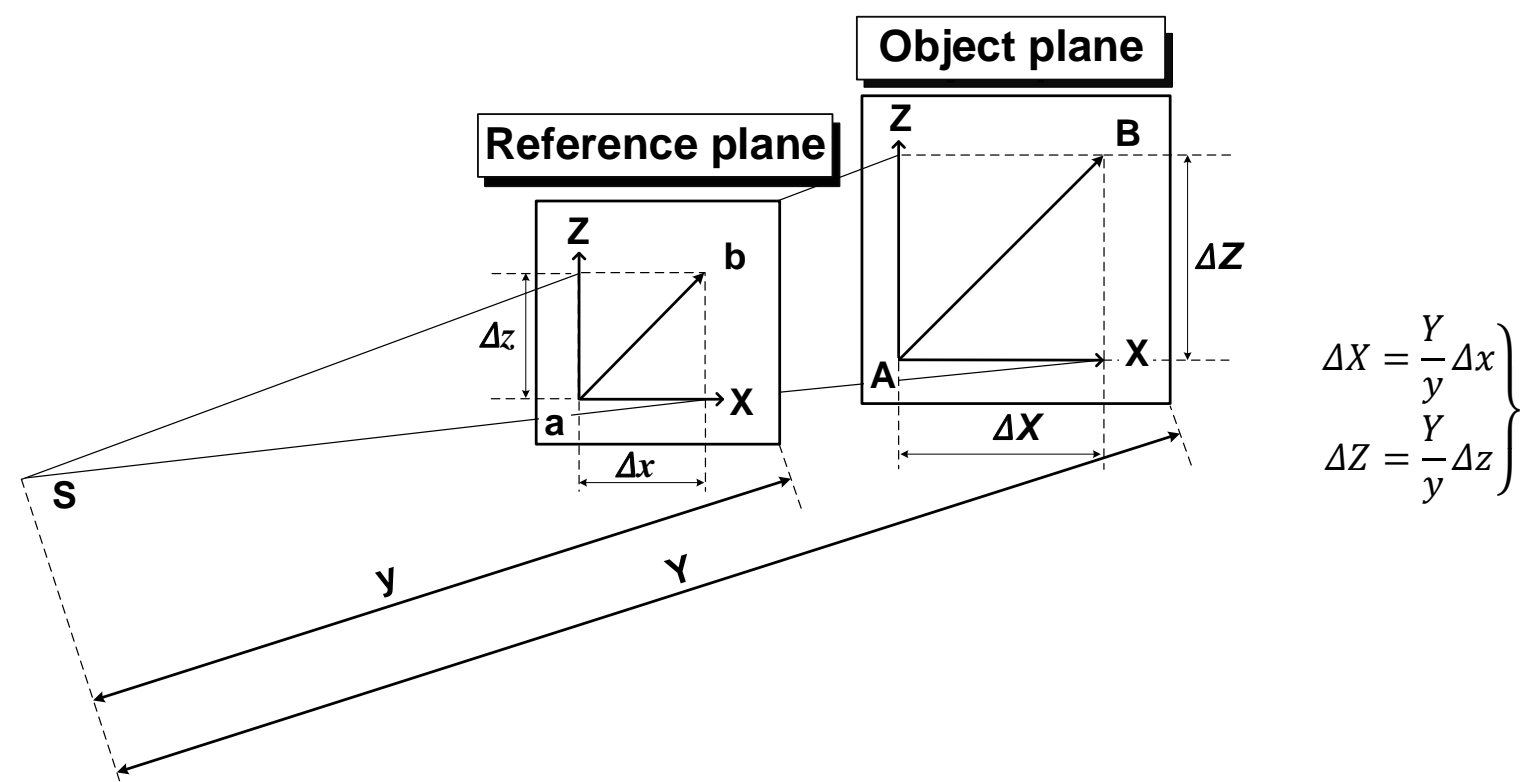

Fig. 7 - Principle of the PST-IM-MP method

Where $\Delta X$ and $\Delta Z$ are the horizontal and vertical initial deformations of the monitoring point on the object plane. Equation (18) is also the core of the PST-IM-MP method [18-20] (Zhang 2018).

\section{Zero-centered motion parallax of monitoring points on the object plane}

If the structure is in a state of elastic deformation, the deformation of the monitoring structure points in all directions repeatedly changes around their respective equilibrium positions. That is, the deformation of each point is independent. If we take the first image as the zero image (the reference image), the deformation of the monitoring points is obtained based on it, independence of monitoring points will be ignored. Although obtained by monitoring the relative deformation in $X$ and $Z$ direction is available. However, the visual result is not user-friendly. If we calculate the 2-D deformation value of monitoring points on the $X-Z$ plane by using the data directly, it will exaggerate 2-D deformation value monitoring points in different degrees in the $X-Z$ plane. In other words, for the structure is in a state of elastic deformation all the time, the result of the PST-IM-MP method obtained is incorrect. Therefore, it is necessary to select an independent reference position for each monitoring point and improve the PST-IM-MP method. That is, the deformation centralization:

$$
\left.\begin{array}{l}
\Delta X^{\prime}=\Delta X-\frac{\sum \Delta X}{n} \\
\Delta Z^{\prime}=\Delta Z-\frac{\sum \Delta Z}{n}
\end{array}\right\}
$$

Where $\Delta X^{\prime}$ and $\Delta Z^{\prime}$ are the horizontal and vertical final deformations of monitoring point on the object plane. Because we obtained $\Delta X^{\prime}$ and $\Delta Z^{\prime}$ their mean are zero, named zero-centered. 


\section{BUILDING DEFORMATION MONITORING TESTS}

\section{Test process}

The monitoring building tennis stadium is located in Jinan, Shandong Province. Tennis stadium has a building area of about $31400 \mathrm{~m}^{2}$. Reinforced concrete frame shear walls are used for the stands and functional rooms. The wall adopts the folded plate structure in the form of willow leaves, combined with the curtain wall steel columns of the building, to form a diamond lattice column. As Figure 8 shows, the valley depth of the folded plate structure of the outer wall is $3 \mathrm{~m}$ and combined with the steel columns of the curtain wall to form diamond composite columns. The structure contributes to improving the stability of the folded plate structure out of plane. The height of the steel structure decreases from south to north, with the highest elevation is $31.3 \mathrm{~m}$, the lowest point is $21.3 \mathrm{~m}$, and the max span is $38.5 \mathrm{~m}$ [22]. In the test, we used the PDMS to monitor the dynamic deformation of the southeast side of the tennis stadium.

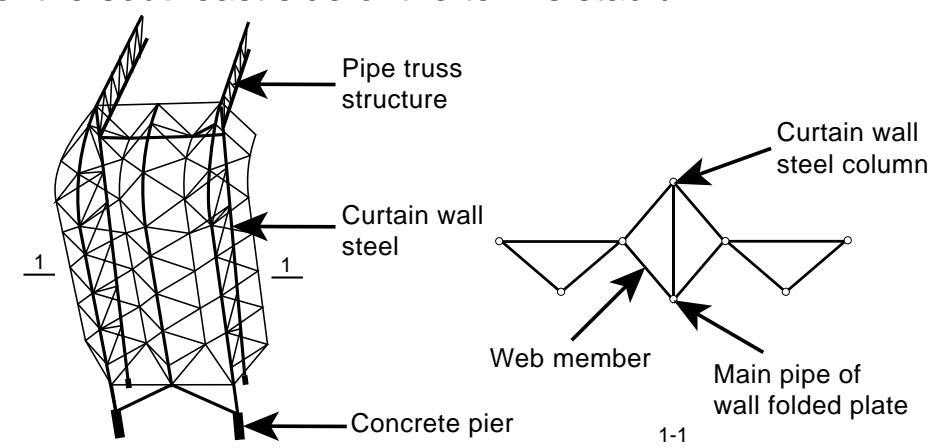

Fig. 8 - Layout of steel structure wall members

Figure 9 (a) shows we set up a camera at a suitable position on the test field, set up a reference plane by two tripods right in front of the camera. We selected 12 points as monitoring points, as Figure 9 (b) shows. Then, we control the camera to shoot them continuously with 12 times as a group, total four groups are shot. In the process, use rangefinder obtained the relative positions of camera and object plane, use steel ruler obtained the relative positions of camera and the reference plane, and the length of reference baselines. Figure 9 (b) shows the reference points and monitoring points used in this test.

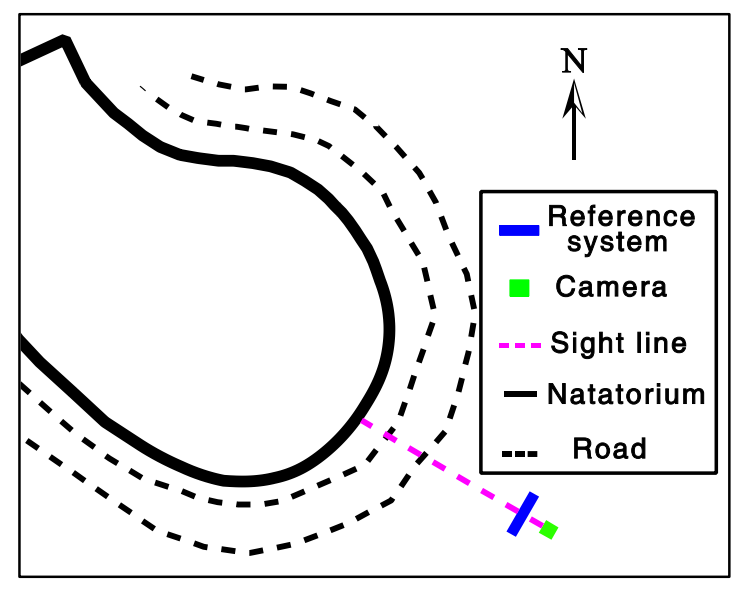

(a) Sketch Map

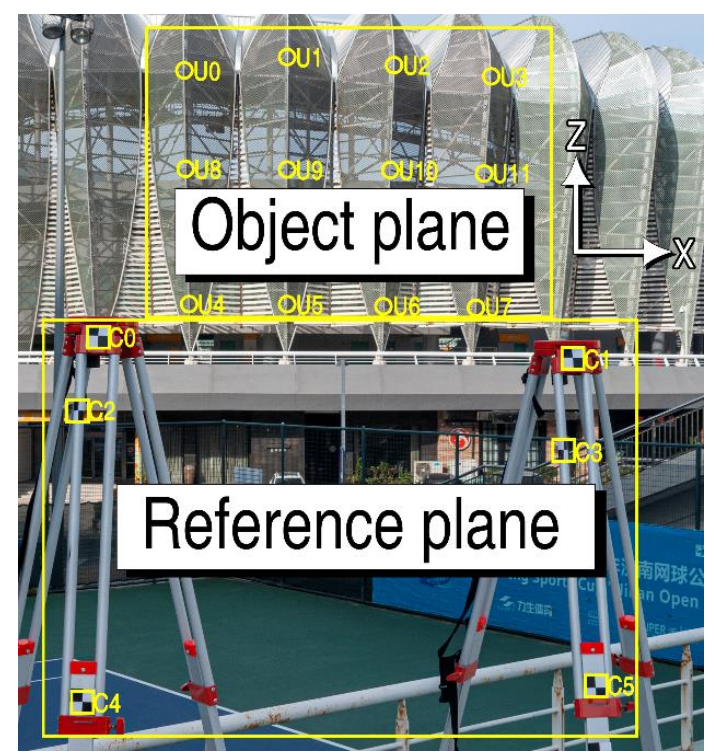

(b) Layout of points

Fig. 9 - Test field 


\section{Results and analysis}

Use the PST-IM-MP method to obtain the deformation of the monitoring points U0-U11, and the deformations of these monitoring points in the $X$ direction and the $Z$ direction, as shown in Table 3 and 4 . For the convenience of the display, only two decimal places were reserved here. Use the Z-MP method to obtain the deformation of monitoring points $\mathrm{U} 0-\mathrm{U} 11$, as shown in Table 5 and 6:

Tab. 3-Deformation of UO-U11 in the $X$ direction $/ \mathrm{mm}$

\begin{tabular}{|c|c|c|c|c|c|c|c|c|c|c|c|c|}
\hline Time/s & $\mathrm{U} 0 \mathrm{x}$ & $\mathrm{U} 1 \mathrm{x}$ & $\mathrm{U} 2 \mathrm{x}$ & $\mathrm{U} 3 \mathrm{x}$ & $\mathrm{U} 4 \mathrm{x}$ & $\mathrm{U} 5 \mathrm{x}$ & $\mathrm{U} 6 \mathrm{x}$ & $\mathrm{U} 7 \mathrm{x}$ & $\mathrm{U} 8_{\mathrm{x}}$ & $\mathrm{U} 9_{\mathrm{x}}$ & $\mathrm{U} 10_{\mathrm{x}}$ & $\mathrm{U} 11_{\mathrm{x}}$ \\
\hline 0 & 12.91 & 6.58 & -81.07 & -3.89 & 59.20 & 53.59 & 48.06 & 42.97 & 15.13 & 9.34 & 3.56 & 39.24 \\
\hline 1 & 46.45 & 46.95 & -35.10 & 25.50 & 59.79 & 59.91 & 39.55 & 39.63 & 2.49 & 2.53 & 23.14 & 23.09 \\
\hline 2 & 79.98 & 87.32 & 10.88 & 54.88 & 60.38 & 66.23 & 31.03 & 36.28 & -10.16 & -4.29 & 42.72 & 6.94 \\
\hline 3 & -30.66 & -24.56 & -58.96 & -11.81 & 55.72 & 20.63 & -14.55 & -9.16 & -28.78 & -22.59 & -16.48 & -51.85 \\
\hline 4 & -9.59 & -12.22 & -56.18 & -18.26 & -13.41 & 24.88 & -18.66 & 19.86 & -11.20 & -54.93 & -57.68 & -19.30 \\
\hline 5 & 19.25 & 5.38 & -47.24 & -55.26 & 41.88 & 30.20 & -22.19 & 8.10 & -12.22 & -24.13 & -36.20 & -6.03 \\
\hline 6 & 72.85 & 30.15 & -14.44 & 62.35 & 53.22 & 91.45 & 7.04 & 4.60 & -17.22 & 20.77 & 17.95 & 15.14 \\
\hline 7 & -30.52 & -72.78 & -112.42 & -68.06 & -5.63 & 35.51 & -5.28 & -46.01 & -102.04 & -60.67 & -60.44 & -59.85 \\
\hline 8 & -34.57 & -45.52 & -94.23 & -98.21 & 37.33 & 28.86 & -61.28 & 12.80 & -62.54 & -30.21 & -38.94 & -46.36 \\
\hline 9 & 14.37 & -14.43 & -82.59 & -66.66 & 50.20 & 43.30 & -24.86 & 30.21 & -61.04 & -27.20 & -34.33 & -20.11 \\
\hline 10 & 63.31 & 16.67 & -70.94 & -35.11 & 63.07 & 57.73 & 11.57 & 47.61 & -59.53 & -24.19 & -29.72 & 6.15 \\
\hline
\end{tabular}

Tab. 4 - Deformation of UO-U11 in the Z direction $/ \mathrm{mm}$

\begin{tabular}{|c|c|c|c|c|c|c|c|c|c|c|c|c|}
\hline Time/s & $\mathrm{UO}_{\mathrm{z}}$ & $\mathrm{U} 1_{z}$ & $\mathrm{U} 2 \mathrm{z}$ & $\mathrm{U} 3_{z}$ & $\mathrm{U} 4 \mathrm{z}$ & U5z & $\mathrm{U} 6_{\mathrm{z}}$ & $\mathrm{U} 7_{\mathrm{z}}$ & U8z & $\cup 9_{z}$ & $\mathrm{U} 1 \mathrm{z}_{\mathrm{z}}$ & $\mathrm{U} 11 \mathrm{z}$ \\
\hline 0 & -62.69 & 22.39 & 107.28 & -12.92 & 17.31 & -20.69 & 23.11 & 66.67 & -63.44 & -19.50 & 24.43 & 27.16 \\
\hline 1 & -76.00 & 6.54 & 69.79 & -50.19 & 18.92 & -20.80 & 0.87 & 42.98 & -70.56 & -28.19 & -6.41 & -5.06 \\
\hline 2 & -89.31 & -9.32 & 32.29 & -87.46 & 20.52 & -20.90 & -21.38 & 19.28 & -77.68 & -36.87 & -37.24 & -37.27 \\
\hline 3 & -62.00 & -60.59 & -15.41 & -90.86 & -33.22 & -71.36 & -68.62 & -24.98 & -49.94 & -5.72 & -84.72 & -81.66 \\
\hline 4 & -31.30 & -73.01 & -31.10 & -69.46 & -13.77 & -54.47 & -54.25 & -54.00 & -64.94 & -23.55 & -64.21 & -22.75 \\
\hline 5 & -121.06 & -117.43 & -68.94 & -99.20 & -39.57 & -74.94 & -69.58 & -23.50 & -104.08 & -57.01 & -92.12 & -86.33 \\
\hline 6 & -42.26 & -1.71 & 39.63 & -82.01 & 7.11 & 7.20 & -33.70 & -33.62 & -38.73 & -38.59 & -38.49 & 2.65 \\
\hline 7 & -0.54 & -83.38 & 40.18 & -80.60 & 15.24 & -25.69 & -25.69 & -25.65 & -34.91 & -34.75 & -75.66 & -34.44 \\
\hline 8 & -41.49 & -83.30 & 40.14 & -80.52 & 15.22 & -25.67 & -25.67 & -25.63 & -34.89 & -34.72 & -75.59 & 6.53 \\
\hline 9 & -34.68 & -59.43 & 20.28 & -61.30 & 28.44 & -15.30 & -38.59 & -20.65 & -45.87 & -7.64 & -71.94 & 7.62 \\
\hline 10 & -27.86 & -35.56 & 0.41 & -42.08 & 41.66 & -4.92 & -51.50 & -15.66 & -56.85 & 19.44 & -68.29 & 8.71 \\
\hline
\end{tabular}

Tab. 5 - Zero-centered deformation of U0-U11 in the $X$ direction $/ \mathrm{mm}$

\begin{tabular}{|c|c|c|c|c|c|c|c|c|c|c|c|c|}
\hline Time/s & $\mathrm{U} 0_{\mathrm{x}}$ & $\mathrm{U} 1_{\mathrm{x}}$ & $\mathrm{U} 2_{\mathrm{x}}$ & $\mathrm{U} 3_{\mathrm{x}}$ & $\mathrm{U} 4_{\mathrm{x}}$ & $\mathrm{U} 5_{\mathrm{x}}$ & $\mathrm{U} 6_{\mathrm{x}}$ & $\mathrm{U} 7_{\mathrm{x}}$ & $\mathrm{U} 8_{\mathrm{x}}$ & $\mathrm{U} 9_{\mathrm{x}}$ & $\mathrm{U} 10_{\mathrm{x}}$ & $\mathrm{U} 11_{\mathrm{x}}$ \\
\hline 0 & -5.62 & 4.44 & -22.68 & 15.61 & 17.22 & 7.02 & 48.93 & 25.98 & 46.69 & 28.94 & 20.51 & 46.69 \\
\hline 1 & 27.92 & 44.81 & 23.29 & 45.00 & 17.81 & 13.34 & 40.42 & 22.64 & 34.04 & 22.12 & 40.09 & 14.48 \\
\hline 2 & 61.46 & 85.18 & 69.27 & 74.38 & 18.40 & 19.66 & 31.90 & 19.29 & 21.40 & 15.31 & 59.67 & -17.74 \\
\hline 3 & -49.19 & -26.70 & -0.57 & 7.69 & 13.74 & -25.94 & -13.68 & -26.15 & 2.78 & -2.99 & 0.47 & -62.13 \\
\hline 4 & -28.12 & -14.36 & 2.21 & 1.24 & -55.39 & -21.69 & -17.79 & 2.87 & 20.36 & -35.33 & -40.73 & -3.22 \\
\hline 5 & 0.73 & 3.24 & 11.15 & -35.76 & -0.10 & -16.37 & -21.32 & -8.89 & 19.34 & -4.53 & -19.25 & -66.80 \\
\hline 6 & 54.33 & 28.01 & 43.95 & 81.85 & 11.24 & 44.88 & 7.91 & -12.39 & 14.34 & 40.37 & 34.90 & 22.18 \\
\hline 7 & -49.05 & -74.92 & -54.03 & -48.56 & -47.61 & -11.06 & -4.41 & -63.00 & -70.48 & -41.07 & -43.49 & -14.91 \\
\hline 8 & -53.10 & -47.66 & -35.84 & -78.71 & -4.65 & -17.71 & -60.41 & -4.19 & -30.98 & -10.61 & -21.99 & 26.06 \\
\hline 9 & -4.16 & -16.57 & -24.20 & -47.16 & 8.22 & -3.28 & -23.99 & 13.22 & -29.48 & -7.60 & -17.38 & 27.15 \\
\hline 10 & 44.79 & 14.53 & -12.55 & -15.61 & 21.09 & 11.16 & 12.44 & 30.62 & -27.97 & -4.59 & -12.77 & 28.24 \\
\hline
\end{tabular}

Tab. 6-Zero-centered deformation of U0-U11 in the Z direction $/ \mathrm{mm}$

\begin{tabular}{|c|c|c|c|c|c|c|c|c|c|c|c|c|}
\hline Time/s & $\mathrm{U} 0 \mathrm{z}$ & $\mathrm{U} 1 \mathrm{z}$ & $\mathrm{U} 2 \mathrm{z}$ & $\mathrm{U} 3_{\mathrm{z}}$ & $\mathrm{U} 4_{\mathrm{z}}$ & $\mathrm{U} 5_{\mathrm{z}}$ & $\mathrm{U} 6 \mathrm{z}$ & $\mathrm{U} 7_{\mathrm{z}}$ & $\mathrm{U} 8_{\mathrm{z}}$ & $\mathrm{U} 9_{\mathrm{z}}$ & $\mathrm{U} 10_{z}$ & $\mathrm{U} 11_{\mathrm{z}}$ \\
\hline 0 & -9.13 & 67.37 & 85.96 & 55.86 & 10.23 & 9.09 & 56.29 & 75.28 & -5.09 & 4.78 & 78.09 & 46.69 \\
\hline 1 & -22.44 & 51.52 & 48.46 & 18.59 & 11.84 & 8.98 & 34.05 & 51.59 & -12.21 & -3.90 & 47.25 & 14.48 \\
\hline 2 & -35.75 & 35.66 & 10.97 & -18.68 & 13.44 & 8.88 & 11.80 & 27.89 & -19.33 & -12.59 & 16.42 & -17.74 \\
\hline 3 & -8.44 & -15.61 & -36.73 & -22.08 & -40.30 & -41.58 & -35.44 & -16.37 & 8.41 & 18.56 & -31.06 & -62.13 \\
\hline 4 & 22.26 & -28.03 & -52.42 & -0.68 & -20.85 & -24.69 & -21.07 & -45.39 & -6.59 & 0.73 & -10.55 & -3.22 \\
\hline 5 & -67.50 & -72.45 & -90.26 & -30.42 & -46.65 & -45.16 & -36.40 & -14.89 & -45.73 & -32.73 & -38.46 & -66.80 \\
\hline 6 & 11.30 & 43.27 & 18.31 & -13.23 & 0.03 & 36.98 & -0.52 & -25.01 & 19.62 & -14.31 & 15.17 & 22.18 \\
\hline 7 & 53.02 & -38.40 & 18.86 & -11.82 & 8.16 & 4.09 & 7.49 & -17.04 & 23.44 & -10.47 & -22.00 & -14.91 \\
\hline 8 & 12.07 & -38.32 & 18.82 & -11.74 & 8.14 & 4.11 & 7.51 & -17.02 & 23.46 & -10.44 & -21.93 & 26.06 \\
\hline 9 & 18.89 & -14.45 & -1.05 & 7.48 & 21.36 & 14.48 & -5.40 & -12.03 & 12.48 & 16.64 & -18.28 & 27.15 \\
\hline 10 & 25.70 & 9.42 & -20.91 & 26.70 & 34.58 & 24.86 & -18.32 & -7.05 & 1.50 & 43.72 & -14.63 & 28.24 \\
\hline
\end{tabular}


Figures $10(\mathrm{a})-(\mathrm{c})$ show the deformation curve of U0 - U11 point in $\mathrm{X}$ and $\mathrm{Z}$ direction generated by the PST-IM-MP method and the Z-MP method. The Z-MP method can shift the deformation curve to the $\mathrm{X}$-axis without changing the relative deformation, and shape variable of the monitoring point fluctuates up and down around the $X$-axis. Figure 10 (d) shows the distribution of the data generated by the two algorithms. We can see that the Z-MP method not only facilitates the intra-group comparison of the monitoring points but also makes the deformation curve more reasonable and makes preparations for the next step to obtain the 2-D deformation of the monitoring points on the $\mathrm{X}-\mathrm{Z}$ plane.
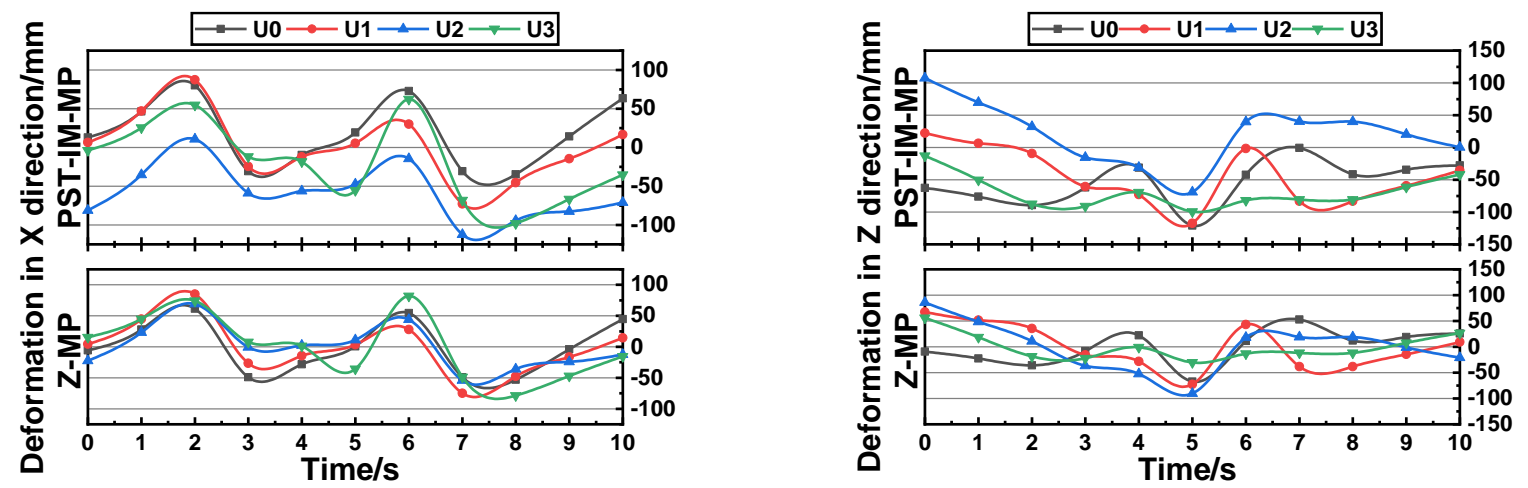

(a) Deformation of U0-U3 in the $X$ and $Z$ directions $/ \mathrm{mm}$
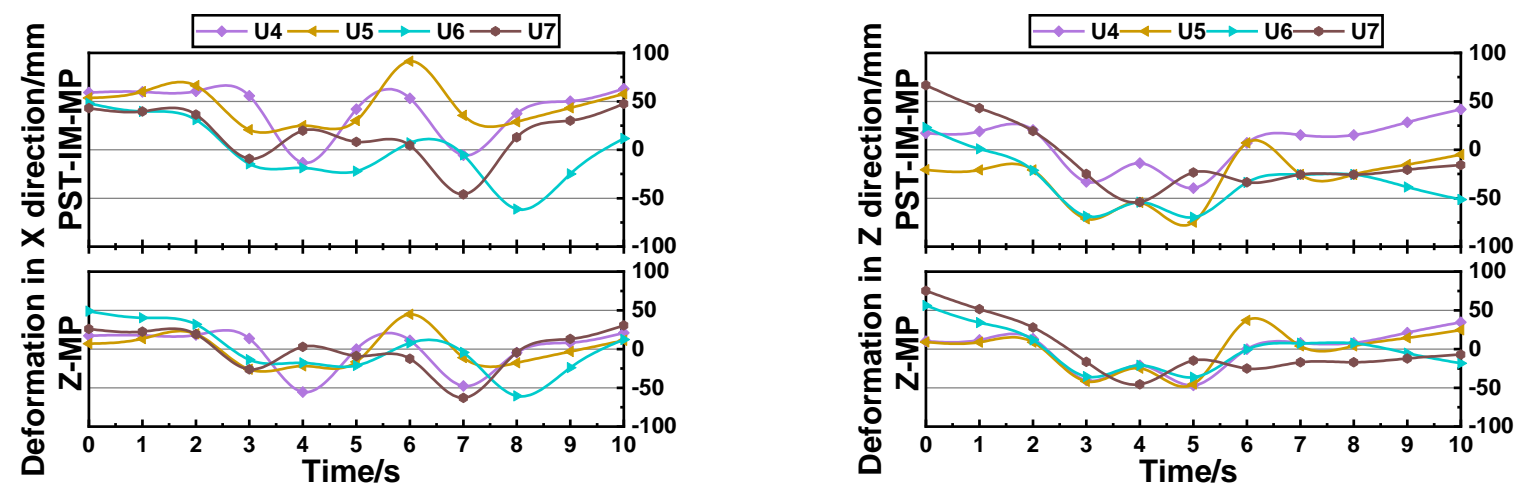

(b) Deformation of U4-U7 in the $X$ and $Z$ directions $/ \mathrm{mm}$
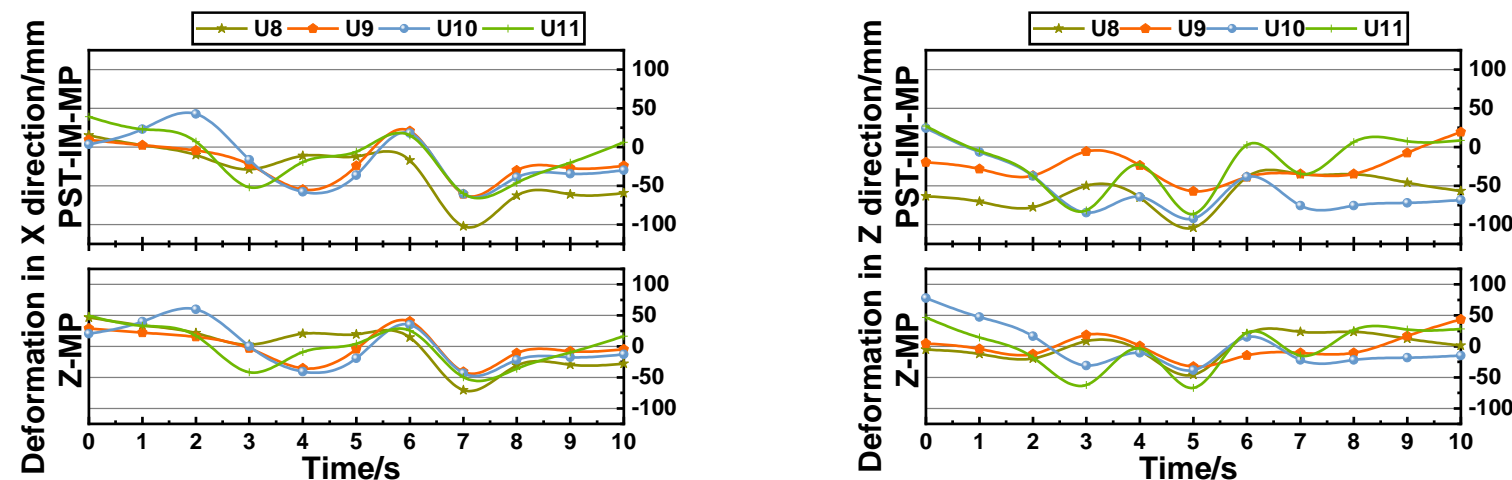

(c) Deformation of U8-U11 in the $X$ and Z directions $/ \mathrm{mm}$

Fig. 10 - Deformation of U0-U11 in the $X$ and Z directions $/ \mathrm{mm}$ 


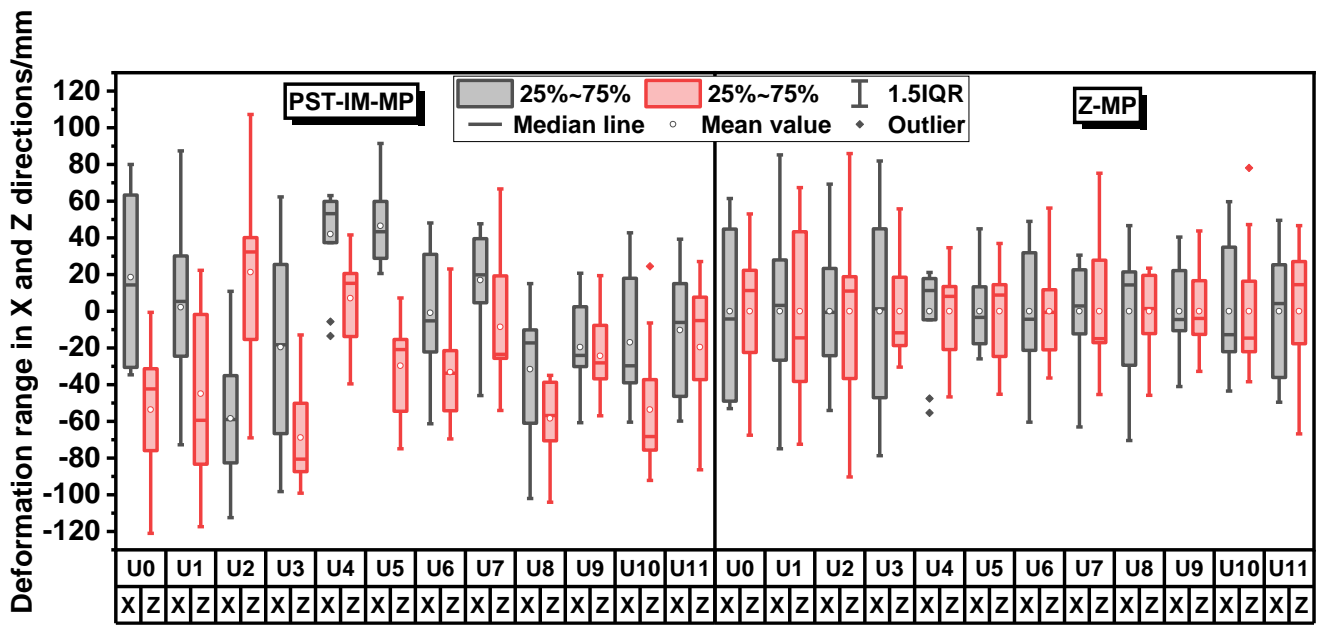

(d) Deformation of U0-U11 in the $X$ and Z directions $/ \mathrm{mm}$

Fig. 10 - Deformation of U0-U11 in the $X$ and $Z$ directions $/ \mathrm{mm}$

The deformations of each monitoring point by the PST-IM-MP method and the Z-MP method in the $X$ direction and the $Z$ direction are obtained as follows, the result as Table 7 and 8 shows.

$$
D i_{x z}^{\prime}=\sqrt{\left(\Delta X^{\prime}\right)^{2}+\left(\Delta Z^{\prime}\right)^{2}}
$$

Tab. 7-Deformation of U0-U11 in the X-Z plane $/ \mathrm{mm}$

\begin{tabular}{|c|c|c|c|c|c|c|c|c|c|c|c|c|}
\hline Time/s & D0xz & D1 xz & D2xz & D3xz & D4xz & D5xz & D6xz & D7xz & D8xz & D9xz & D10xz & D11 xz \\
\hline 0 & 64.01 & 23.34 & 134.47 & 13.49 & 61.68 & 57.45 & 53.33 & 79.32 & 65.22 & 21.62 & 24.69 & 47.72 \\
\hline 1 & 89.07 & 47.40 & 78.11 & 56.29 & 62.71 & 63.42 & 39.55 & 58.46 & 70.60 & 28.30 & 24.01 & 23.64 \\
\hline 2 & 119.89 & 87.82 & 34.07 & 103.25 & 63.77 & 69.45 & 37.68 & 41.08 & 78.34 & 37.12 & 56.67 & 37.91 \\
\hline 3 & 69.17 & 65.38 & 60.94 & 91.62 & 64.87 & 74.28 & 70.15 & 26.61 & 57.64 & 23.30 & 86.31 & 96.73 \\
\hline 4 & 32.74 & 74.03 & 64.21 & 71.82 & 19.22 & 59.88 & 57.37 & 57.54 & 65.90 & 59.77 & 86.31 & 29.83 \\
\hline 5 & 122.58 & 117.55 & 83.57 & 113.55 & 57.62 & 80.80 & 73.03 & 24.86 & 104.79 & 61.91 & 98.98 & 86.54 \\
\hline 6 & 84.22 & 30.20 & 42.18 & 103.02 & 53.69 & 91.73 & 34.43 & 33.93 & 42.39 & 43.82 & 42.47 & 15.37 \\
\hline 7 & 30.52 & 110.68 & 119.38 & 105.49 & 16.25 & 43.83 & 26.23 & 52.68 & 107.85 & 69.92 & 96.84 & 69.05 \\
\hline 8 & 54.00 & 94.93 & 102.42 & 127.00 & 40.31 & 38.62 & 66.44 & 28.65 & 71.61 & 46.02 & 85.03 & 46.82 \\
\hline 9 & 37.53 & 61.16 & 85.04 & 90.56 & 57.70 & 45.92 & 45.90 & 36.59 & 76.35 & 28.25 & 79.71 & 21.50 \\
\hline 10 & 69.17 & 39.27 & 70.94 & 54.80 & 75.59 & 57.94 & 52.78 & 50.12 & 82.31 & 31.03 & 74.48 & 10.66 \\
\hline
\end{tabular}

Tab. 8 - Zero-centered deformation of UO-U11 in the X-Z plane $/ \mathrm{mm}$

\begin{tabular}{|c|c|c|c|c|c|c|c|c|c|c|c|c|}
\hline Time/s & D0xz & D1 $x z$ & D2xz & D3xz & D4xz & D5xz & D6xz & D7 xz & D8xz & D9 $\times z$ & D10xz & D11 xz \\
\hline 0 & 10.72 & 67.52 & 88.90 & 58.00 & 20.03 & 11.48 & 74.58 & 79.64 & 46.96 & 29.33 & 80.74 & 68.05 \\
\hline 1 & 35.82 & 68.28 & 53.77 & 48.69 & 21.39 & 16.08 & 52.84 & 56.34 & 36.16 & 22.46 & 61.97 & 36.36 \\
\hline 2 & 71.10 & 92.34 & 70.13 & 76.69 & 22.79 & 21.57 & 34.01 & 33.92 & 28.83 & 19.82 & 61.88 & 24.71 \\
\hline 3 & 49.90 & 30.93 & 36.74 & 23.38 & 42.58 & 49.01 & 37.99 & 30.85 & 8.86 & 18.80 & 31.07 & 74.76 \\
\hline 4 & 35.86 & 31.49 & 52.47 & 1.42 & 59.18 & 32.87 & 27.57 & 45.48 & 21.39 & 35.34 & 42.08 & 9.59 \\
\hline 5 & 67.50 & 72.52 & 90.95 & 46.94 & 46.65 & 48.04 & 42.18 & 17.34 & 49.65 & 33.04 & 43.01 & 66.93 \\
\hline 6 & 55.49 & 51.55 & 47.61 & 82.92 & 11.24 & 58.15 & 7.93 & 27.91 & 24.30 & 42.83 & 38.05 & 33.73 \\
\hline 7 & 72.23 & 84.19 & 57.23 & 49.97 & 48.30 & 11.79 & 8.69 & 65.26 & 74.28 & 42.39 & 48.74 & 51.78 \\
\hline 8 & 54.45 & 61.15 & 40.48 & 79.58 & 9.38 & 18.18 & 60.88 & 17.52 & 38.87 & 14.89 & 31.06 & 44.52 \\
\hline 9 & 19.34 & 21.98 & 24.22 & 47.75 & 22.89 & 14.85 & 24.59 & 17.87 & 32.01 & 18.30 & 25.23 & 28.88 \\
\hline 10 & 51.64 & 17.32 & 24.39 & 30.93 & 40.51 & 27.25 & 22.14 & 31.42 & 28.01 & 43.96 & 19.42 & 32.67 \\
\hline
\end{tabular}




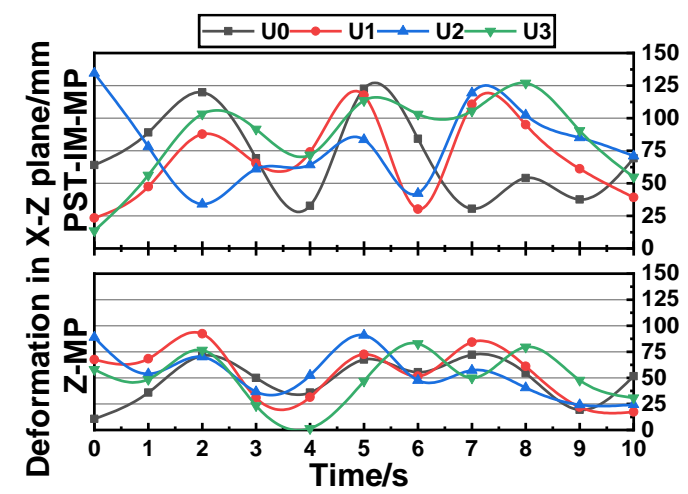

(a) Deformation of U0-U3 in the X-Z plane $/ \mathrm{mm}$

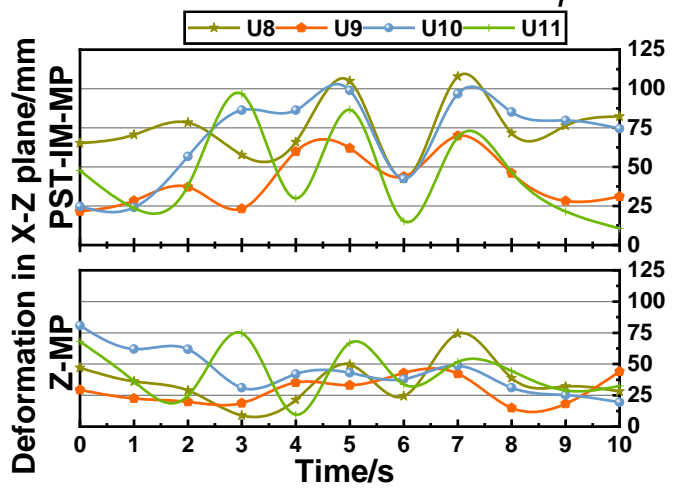

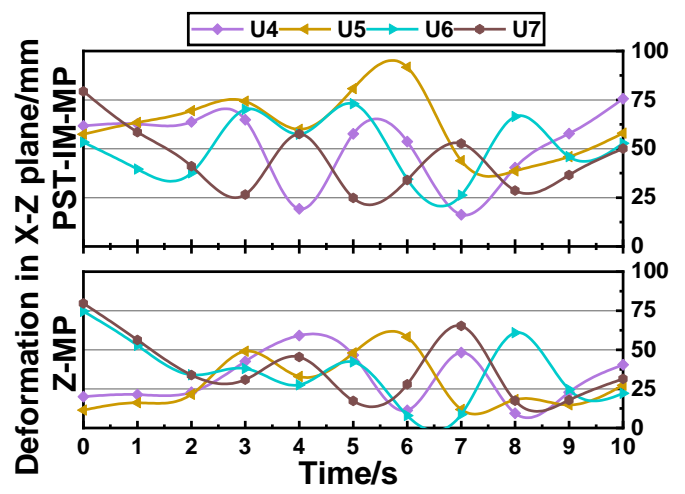

(b) Deformation of U4-U7 in the $X-Z$ plane $/ \mathrm{mm}$

Figure 11 shows the deformation curve of each monitoring point on the $X-Z$ plane by two methods. (a)-(c) show the difference of the deformation curve of each monitoring point generated by the PST-IM-MP method and the Z-MP method. The Z-MP method can reduce the situation in which deformation calculated by the PST-IM-MP method is exaggerated to varying degrees.

(c) Deformation of U8-U11 in the $X-Z$ plane $/ \mathrm{mm}$

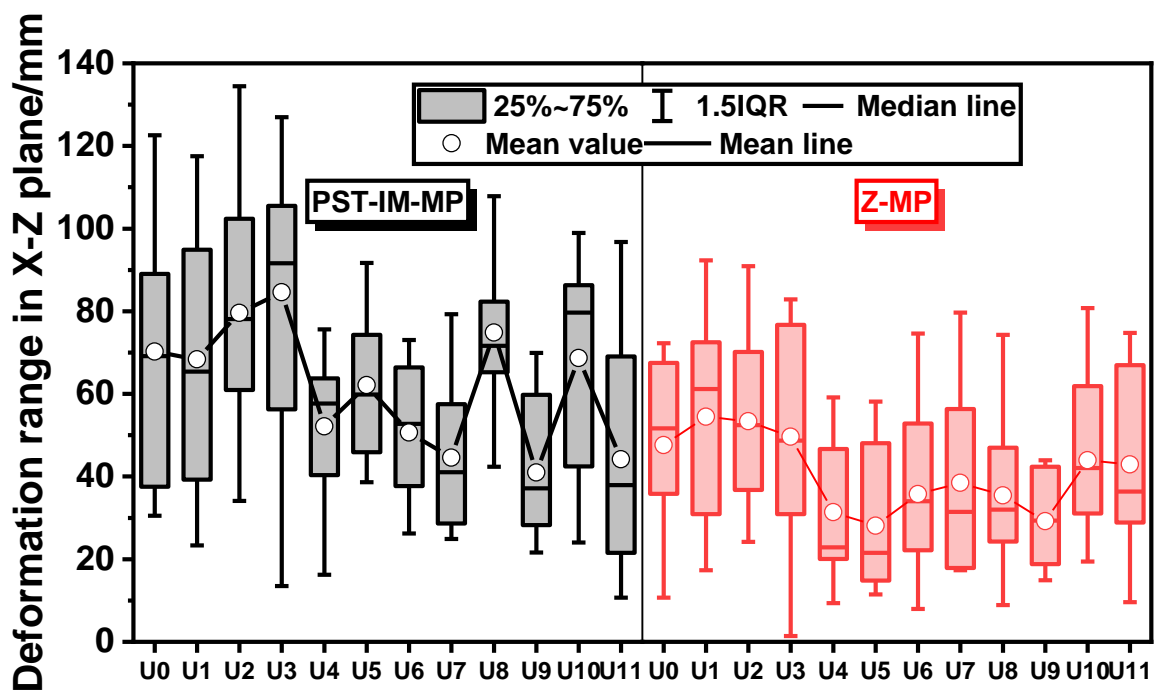

(d) Deformation of U0-U11 in the X-Z plane $/ \mathrm{mm}$

Fig. 11 - Deformation of U0-U11 in the X-Z plane/mm

The observation of three deformation curves generated by the Z-MP method shows that the three groups of points are undergoing elastic deformation, and the monitoring structure is in a stable equilibrium state. The observation of three deformation curves generated by the Z-MP method shows that the three groups of points are undergoing elastic deformation, and the monitoring structure is in a stable equilibrium state. If U0-U3, U4-U7, and U8-U11 group the data, they correspond to the upper, lower, and middle parts of the monitoring building. By comparing the deformation values of these three groups of points, it can be found that: U0-U3 group is the largest, 
U8-U11 group is the second, and U4-U7 group is the smallest. Therefore, it can be determined: for the whole structure, the height of the monitoring structure is correlated positively with the deformation range on the whole. However, according to the analysis above, the deformation value and deformation interval of U9 point are the smallest, indicating that there may be abnormal deformation near U9 point, which hinders the normal elastic deformation of this point. If the deformation value and deformation interval of $\mathrm{U} 1$ and $\mathrm{U} 3$ are the largest, the nearby parts of these points are undergoing relatively large and rapid elastic deformation, prone to damage accumulation and resistance attenuation. Relevant safety maintenance personnel should find out the deformation's reasons and further refine the deformation observation of these parts to ensure the healthy and safe operation of tennis courts.

\section{CONCLUSION}

(1) If the spatial structure in a state of elastic deformation, the deformation value using the PST-IM-MP method obtained is available. However, the deformation curve by using these data generated is not user-friendly. If we obtain the 2-D deformation value of monitoring points in the $X$ $Z$ plane by directly using the data, it will exaggerate the 2-D deformation in the $X-Z$ plane of points at different levels. This paper offered the Z-MP method to solve these problems effectively.

(2) This paper proposed the PDMS to use for non-contact dynamic deformation monitoring of complex structures. Moreover, PDMS is robust, easy realizing, economical, and highly automatic, can apply to amounts of complex scenarios.

(3) For the tennis stadium, the height of the monitoring structure is positively correlating with the deformation range.

(4) According to the deformation monitoring, the maximum deflection of the monitoring points is $92.34 \mathrm{~mm}$, which conforms to the design standard [23]. The tennis stadium's spatial structure is safe on the whole, but there are still a few abnormal deformation values that need to be verified by relevant security personnel.

\section{ACKNOWLEDGEMENTS}

This paper was supported by the Science and Technology Project of the Shandong Province of China (Grant No.2010GZX20125). The funders Chengxin Yu was involved in the editing and approval of the manuscript and decision to publish this paper.

\section{REFERENCES}

[1] Kabando E.K., Gong J., 2019. An overview of long-span spatial grid structures failure case studies. Asian Journal of Civil Engineering. Vol. 20. No. 8: 1137-1152. doi: 10.1007/s42107-019-00168-4

[2] Dong S.L., Luo Y.Z., Zhao Y., 2005. Practical application and research advances of long-span space structures. SPATIAL STRUCTURES. Vol. 11. No. 4: 3-10. doi: 10.3969/j.issn.1006-6578.2005.04.001

[3] Investigation C., 2009. On the roof collapse at Stadium Sultan Mizan Zainal Abidin: Final report on the roof collapse at Stadium Sultan Mizan Zainal Abidin, Terengganu, Malaysia.

[4] Board D.S., 2012. Roof collapse during extension work at the stadium of FC Twente in Enshede Netherlands.

[5] Department B., 2017. Final investigation report on the collapse of roof structure of Chan Tai Ho Multipurpose Hall of HU Fa Kuang Sports center of City University of Hong Kong at Chee Avenue, Kowloon

[6] Luo Y.Z., Shen Y.B., Tong R.F., Wang X.B., 2009. Health Monitoring and Early Warning Health Monitoring and Early Warning Technology in Spatial Structure. CONSTRUCTION TECHNOLOGY. Vol. 38. No. 03: 4-8.

[7] Sabamehr A., Lim C., Bagchi A., 2018. System identification and model updating of highway bridges 
using ambient vibration tests. Journal of Civil Structural Health Monitoring. Vol. 8. No.755-771. doi: 10.1007/s13349-018-0304-5

[8] Doebling S.W., Farrar C.R., Prime M.B., Shevitz D.W., 1996. Damage Identification and Health Monitoring of Structural and Mechanical Systems from Changes in Their Vibration Characteristics: A Literature Review. Vol. doi: 10.2172/249299

[9] Goda I., L'Hostis G., Guerlain P., 2019. In-situ non-contact 3D optical deformation measurement of large capacity composite tank based on close-range photogrammetry. Optics and Lasers in Engineering. Vol. 119. No.37-55. doi: 10.1016/j.optlaseng.2019.02.006

[10] Zhou X., 2010. STRUCTURAL DESIGN AND HEALTH MONITORING OF JINAN OLYMPIC SPORTS CENTER. Engineering Mechanics. No. A02: 105-113.

[11] Xu J., Xi N., Zhang C., Zhao J.G., Gao B.T., Shi Q., 2011. Rapid 3D surface profile measurement of industrial parts using two-level structured light patterns. Optics and Lasers in Engineering. Vol. 49. No. 7: 907-914. doi: 10.1016/j.optlaseng.2011.02.010

[12] Xu X.Y., Yang H., Neumann I., 2018. Monotonic loads experiment for investigation of composite structure based on terrestrial laser scanner measurement. Composite Structures. Vol. 183. No.563-567. doi: 10.1016/j.compstruct.2017.07.001

[13] Cuypers W., Van Gestel N., Voet A., Kruth J.P., Mingneau J., Bleys P., 2009. Optical measurement techniques for mobile and large-scale dimensional metrology. Optics and Lasers in Engineering. Vol. 47. No. 3: 292-300. doi: https://doi.org/10.1016/j.optlaseng.2008.03.013

[14] Urbanová P., Hejna P., Jurda M., 2015. Testing photogrammetry-based techniques for threedimensional surface documentation in forensic pathology. Forensic Science International. Vol. 250. No.7786. doi: $10.1016 /$ j.forsciint.2015.03.005

[15] Yu C.X., Song C.Z., Tong Y.B., Li X.L., Quan J., Xu F., 2001. Digital Photographic and Computer Technology in Real-time Monitored Structural Deformation. JOURNAL OF JINAN UNIVERSITY. Vol. 15. No. 3: 232-234. doi: 10.3969/j.issn.1671-3559.2001.03.014

[16] Chen M.Z., 2012. The Application and Comparison of Digital Ground Photogrammetry Technology for Bridge Safety Monitoring. Applied Mechanics and Materials. Vol. 170-173. No.2979-2986. doi: 10.4028/www.scientific.net/AMM.170-173.2979

[17] Zhang G.J., Yu C.X., Guo G.L., 2017. Application of digital close-range photogrammetry in the deformation observation of check gate. JOURNAL OF SHANDONG UNIVERSITY (ENGINEERING SCIENCE). Vol. 47. No. 06: 46-51.

[18] Yu C.X., Zhang G.J., Ding X.H., Zhao Y.Q., Guo G.L., 2019. MONITORING DYNAMIC DEFORMATION OF SHUTTLE STEEL SHELVES BY DIGITAL PHOTOGRAPHY. Civil Engineering Journal. Vol. 28. No. 2: 136-150. doi: 10.14311/CEJ.2019.02.0012

[19] Zhang G.J., Guo G.L., Yu C.X., Li L., Wang X., 2018. Monitoring Instantaneous Dynamic Displacements of Masonry Walls in Seismic Oscillation Outdoors by Monocular Digital Photography. Mathematical Problems in Engineering. Vol. 2018. 1-15. doi: 10.1155/2018/4316087

[20] Yu C.X., Zhang G.J., Ding X.H., Zhao Y.Q., Guo G.L., 2019. MONITORING DYNAMIC GLOBAL DEFLECTION OF A BRIDGE BY MONOCULAR DIGITAL PHOTOGRAPHY. Civil Engineering Journal. Vol. 27. No. 14: 168-182. doi: 10.14311/CEJ.2018.02.0014

[21] Wang P.J., Xu Y.M.: photogrammetry. Wuhan university press: Wuhan (2016)

[22] Zhou Y., Fu X.Y., Yang X.B., 2008. Structural design of Tennis Gymnasium of Ji Nan Olympic Sports Center. SPATIALS TRUCTURES. Vol. 14. No. 04: 26-31.

[23] GB50017-2017, 2017. Steel structure design standard. China Standards Press.

[24] Feng W.H., 2002, Close Range Photogrammetry: Measuring an Object Shape and Motion State Imaging Method, section 8.5 (Wuhan University Press) 179 pp.

[25] Ge Y.Q., Yu C.X., Liu X.D., Wang R.H., 2020. Monitoring dynamic deformation of communication tower using photography dynamic monitoring system. IOP Conference Series: Earth and Environmental Science. Vol. 558. No. 2: doi: 10.1088/1755-1315/558/2/022061 